\title{
Detection of Impaired Cognitive Function in Rat with Hepatosteatosis Model and Improving Effect of GLP-1 Analogs (Exenatide) on Cognitive Function in Hepatosteatosis
}

\author{
Oytun Erbaş, ${ }^{1}$ Fulden Sarac, ${ }^{2,3}$ Hüseyin Aktuğ, ${ }^{4}$ and Gönül Peker ${ }^{5}$ \\ ${ }^{1}$ Department of Physiology, Faculty of Medicine, Gaziosmanpasa University, Tokat, Turkey \\ ${ }^{2}$ Department of Internal Medicine, School of Medicine, Ege University, Izmir, Turkey \\ ${ }^{3}$ Department of Geriatrics Medicine, Medical Faculty, Ege University, 5th Floor, Bornova, \\ 35100 Izmir, Turkey \\ ${ }^{4}$ Department of Histology and Embryology, School of Medicine, Ege University, Izmir, Turkey \\ ${ }^{5}$ Department of Physiology, School of Medicine, Ege University, Izmir, Turkey
}

Correspondence should be addressed to Fulden Sarac; fuldensarac@yahoo.com

Received 20 September 2013; Accepted 22 January 2014; Published 11 March 2014

Academic Editors: P. Campiglia, G. Iaccarino, and N. Montuori

Copyright (c) 2014 Oytun Erbaş et al. This is an open access article distributed under the Creative Commons Attribution License, which permits unrestricted use, distribution, and reproduction in any medium, provided the original work is properly cited.

The aims of the study were to evaluate (1) detection of cognitive function changing in rat with hepatosteatosis model and (2) evaluate the effect of GLP-1 analog (exenatide) on cognitive function in hepatosteatosis. In the study group, $30 \%$ fructose was given in nutrition water to perform hepatosteatosis for 8 weeks to 18 male rats. Six male rats were chosen as control group and had normal nutrition. Fructose nutrition group were stratified into 3 groups. In first group $(n=6)$, intracerebroventricular (ICV) infusion of exenatide $(n=6)$ was given. ICV infusion of $\mathrm{NaCl}(n=6)$ was given to second group. And also, the third group had no treatment. And also, rats were evaluated for passive avoidance learning (PAL) and liver histopathology. Mean levels of latency time were statistically significantly decreased in rats with hepatosteatosis than those of normal rats $(P<0.00001)$. However, mean level of latency time in rats with hepatosteatosis treated with ICV exenatide was statistically significantly increased than that of rats treated with $\mathrm{ICV} \mathrm{NaCl}(P<0.001)$. Memory performance falls off in rats with hepatosteatosis feeding on fructose (decreased latency time). However, GLP-1 ameliorates cognitive functions (increased latency time) in rats with hepatosteatosis and releated metabolic syndrome.

\section{Introduction}

The metabolic syndrome (MetS), a disease arising from the worldwide epidemic of obesity, is manifested as severe insulin resistance, hyperlipidaemia, hepatic steatosis, and diabetes [1]. And also MetS has been shown to predispose cognitive impairment [2-4]. Recent studies addressing the association of MetS with cognitive performance and risk for dementia report mixed results [5-7]. Potential explanatory models include impaired vascular reactivity, neuroinflammation, oxidative stress, and abnormal brain lipid metabolism [8]. In a study, Su et al. [9] suggested that rats with the metabolic syndrome have ineffective inflammation-resolving mechanisms that represent plausible reasons for the exaggerated and persistent postoperative cognitive decline. And also inflammation induces deficits in neurotransmitter-releasing neurons such as cholinergic, noradrenergic, and serotonergic neurons [10-12]. In previous studies [13-15], glucagon-like peptide-1 (GLP-1) and its receptor (GLP-1R) modulated neuronal activity and protected against neuronal damage induced by various insults in the brain. And they were involved in learning and memory. However, there were not many studies related to investigating the showing impaired cognitive function in rat with hepatosteatosis and GLP1 effect on cognitive function. Therefore, the aims of the study were to evaluate (1) detection of cognitive function 
changing in rat with hepatosteatosis model and (2) evaluate the effect of GLP-1 analog (exenatide) on cognitive function in hepatosteatosis.

\section{Materials and Methods}

2.1. Animals. In this study 24 male Sprague Dawley albino mature rats at 8 weeks, weighing 200-220 g, were used. Animals were fed ad libitum and housed in pairs in steel cages having a temperature-controlled environment $(22 \pm$ $2^{\circ} \mathrm{C}$ ) with $12 \mathrm{~h}$ light/dark cycles. The experimental procedures were approved by the Committee for Animal Research of Ege University. All animal studies are strictly conformed to the animal experiment guidelines of the Committee for Human Care.

2.2. Experimental Protocol. In the study group, $30 \%$ fructose was given in nutrition water to perform hepatosteatosis for 8 weeks to 18 male rats. Six male rats were chosen as control group and had normal nutrition.

Fructose nutrition group were stratified into 3 groups. In the first group $(n=6)$, intracerebroventricular (ICV) infusion of exenatide $(n=6)$ was given. ICV infusion of $\mathrm{NaCl}(n=6)$ was given to the second group. And also the third group had no treatment. ICV injection was performed under anesthetized. Rats were deeply anesthetized by the mixture of ketamine hydrochloride $(40 \mathrm{mg} / \mathrm{kg}$, Alfamine, Ege Vet, Alfasan International B.V., Holland) and xylazine hydrochloric (4 mg/kg, Alfazyne, Ege Vet, Alfasan International B.V., Holland), i.p., and placed in a stereotaxic frame (Figure 1). Exenatide $10 \mu \mathrm{g} / \mathrm{kg}$ (Byetta, Lilly) was infused $10 \mu \mathrm{L}$ into the left lateral ventricle $(\mathrm{AP}=-0.8 \mathrm{~mm} ; \mathrm{ML}=$ $\pm 1.6 \mathrm{~mm} ; \mathrm{DV}=-4.2 \mathrm{~mm}$ ) with a 28 -gauge Hamilton syringe in. Sham-operated rats received vehicle $(10 \mu \mathrm{L}$ isotonic $\mathrm{NaCl})$. The needle was left in place for an additional $2 \mathrm{~min}$ for complete diffusion of the drug. All animals were given penicillin intraperitoneally to prevent postsurgical infection. After surgery, rats were weighed regularly and monitored daily for behavior and health conditions.

After 5-day recovery phase, passive avoidance task evaluating the memory was performed to study and control groups. This passive avoidance learning (PAL) is a one trial fear-motivated avoidance task in which the rat learns to refrain from stepping through a door to an apparently safer but previously punished dark compartment. The PAL box which is equal to the size of dark and light sections used. This box has a grid system which performs electric shock in dark compartment. Normally, rats when placed in the light compartment prefer to enter dark compartment. After $10 \mathrm{sec}$ of habituation, the guillotine door separating the light and dark chambers was opened. When the rat passed to dark compartment, door between the light and dark compartments was closed. Then, $1.5 \mathrm{~mA}$ electric shock was applied for 3 seconds and the rat was removed from the dark chamber and returned to its home cage. After 24 hours, rats were placed in the same mechanism. The time (latency) to switch from light compartment to dark compartment of rats was recorded but foot shock was not delivered, and the latency time was recorded up to a maximum of $300 \mathrm{sec}$. The latency to refrain from crossing into the punished compartment serves as an index of the ability to avoid, and allows memory to be assessed. Then, the animals were euthanized and hepatectomy was performed for histopathological examination.

2.3. Histopathological Examination of Liver. For histological and immunohistochemical studies, all animals were anesthetized by an i.p. of ketamine $(40 \mathrm{mg} / \mathrm{kg}) /$ xylazine $(4 \mathrm{mg} / \mathrm{kg})$ and perfused with $200 \mathrm{~mL}$ of $4 \%$ formaldehyde in $0.1 \mathrm{M}$ phosphate-buffer saline (PBS). Formalin-fixed liver sections $(4 \mu \mathrm{m})$ were stained with hematoxylin-eosin $(\mathrm{H} \& \mathrm{E})$. All sections were photographed with Olympus C-5050 digital camera mounted on Olympus BX51 microscope.

Morphological analysis was assessed by computerized image analysis system (Image-Pro Express 1.4.5, Media Cybernetics, Inc., USA) on ten microscopic fields per section examined at a magnification of $\times 40$, with the observer blind to the study group. The liver pathologic findings were scored as follows [16] steatosis (the percentage of liver cells containing fat). The total liver pathology score was calculated by adding the scores from each parameter:

$$
\begin{aligned}
& 1+, \text { less than } 25 \% \text { of cells containing fat; } \\
& 2+, 26 \% \text { to } 50 \% \text {; } \\
& 3+51 \% \text { to } 75 \% \text {; and } \\
& 4+\text {, more than } 75 \% \text {; } \\
& \text { inflammation and necrosis: one focus/lobul } 1+\text {; } \\
& \text { Two or more foci/lobule } 2+\text {. }
\end{aligned}
$$

2.4. Statistical Analysis. Statistical evaluation was performed using SPSS version 15.0 for Windows. The groups of parametric variables were compared using the Student's $t$-test and analysis of variance. Also, the groups of nonparametric variables were compared using the Mann-Whitney $U$ test. In addition, the Shapiro-Wilk test was used for parametricnonparametric differentiation. Results are presented as mean + SEM. A $P<0.05$ was accepted as statistically significant.

\section{Results}

Macrovesicular hepatosteatosis was shown in rat who had received fructose. It was found that latency time was statistically significantly decreased in rat with hepatosteatosis $(P<0.00001)$ (Figure 2).

Mean levels of latency time in rats with hepatosteatosis treated with ICV GLP-1 analog (exenatide) was statistically significantly increased (memory improvement) than those of rats with hepatosteatosis treated with $\mathrm{ICV}$ isotonic $\mathrm{NaCl}(P<$ 0.001) (Table 1).

Mean levels of histopatologic score of liver were not significantly statistically different in rat with hepatosteatosis treated with ICV NaCl or ICV exenatide or anything $(P>$ 0.05).

Mean levels of latency time were statistically significantly decreased in rats with hepatosteatosis than those of normal 
TABLE 1: Mean levels of latency time and histopathologic score were shown in study and control groups.

\begin{tabular}{lcccc}
\hline & Normal & $\begin{array}{c}\text { Rat with hepatosteatosis } \\
\text { (no treatment) }\end{array}$ & $\begin{array}{c}\text { Rat with hepatosteatosis } \\
\text { and ICV NaCl }\end{array}$ & $\begin{array}{c}\text { Rat with hepatosteatosis } \\
\text { and ICV exenatide }\end{array}$ \\
\hline Latency time $(\mathrm{sec})$ & $161.5 \pm 14.9$ & $16.3 \pm 1.8^{*}$ & $14.1 \pm 0.9^{*}$ & $73.8 \pm 6.4^{*}$ \\
Histopathologic score & $1.14 \pm 0.12$ & $5.38 \pm 0.35^{* *}$ & $5.41 \pm 0.52$ & $5.26 \pm 0.48$ \\
\hline
\end{tabular}

Results were presented as mean \pm SEM. ${ }^{*} P<0.00001,{ }^{* *} P<0.05$ different from normal groups; ${ }^{\#} P<0.001$ different from rat with hepatosteatosis (no treatment) and rat with hepatosteatosis given ICV NaCl.

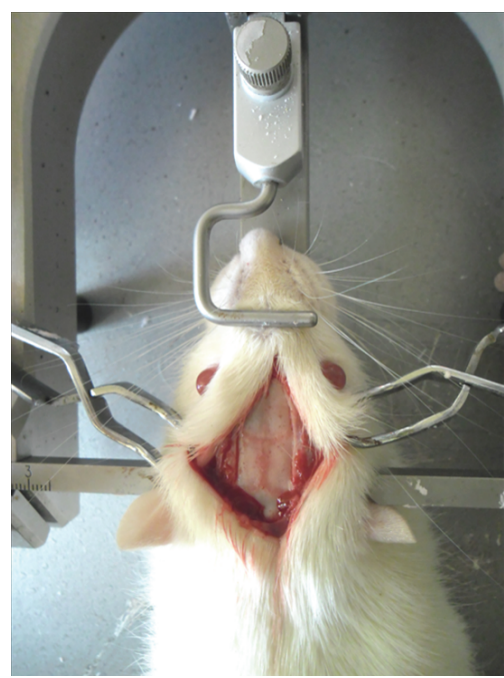

(a)

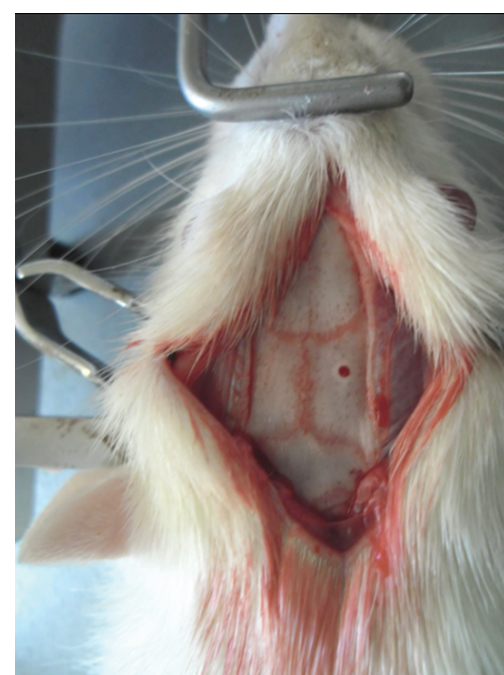

(b)

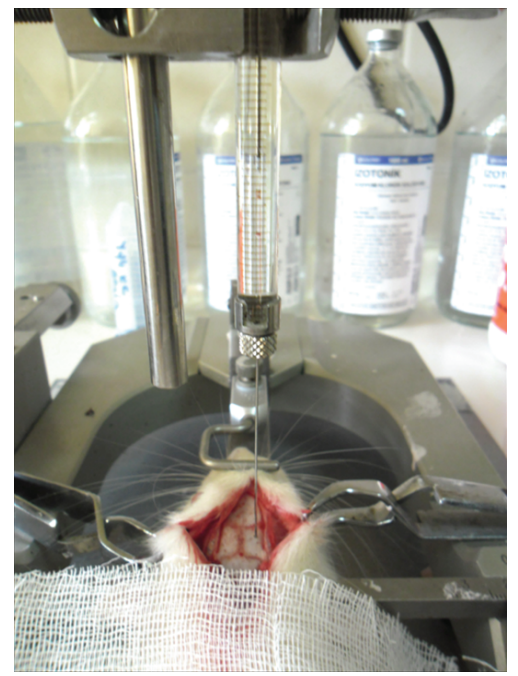

(c)

FIGURE 1: Stereotaxical infusion protocol was shown in rat.

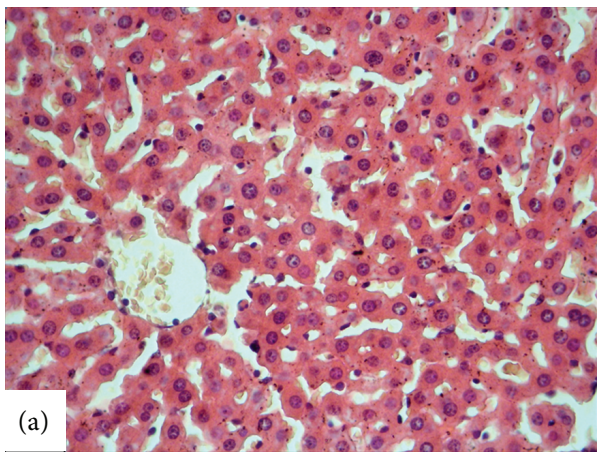

(a)

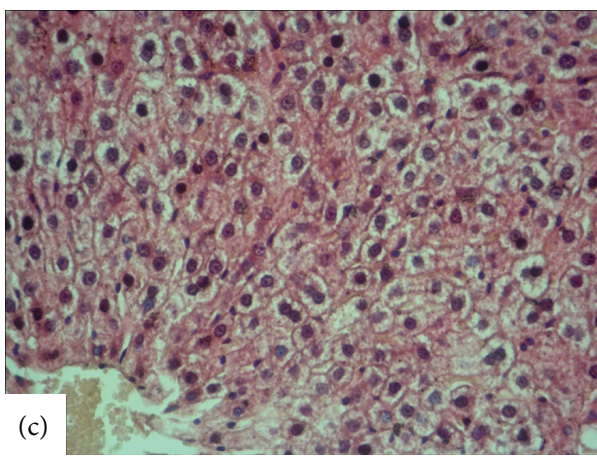

(c)

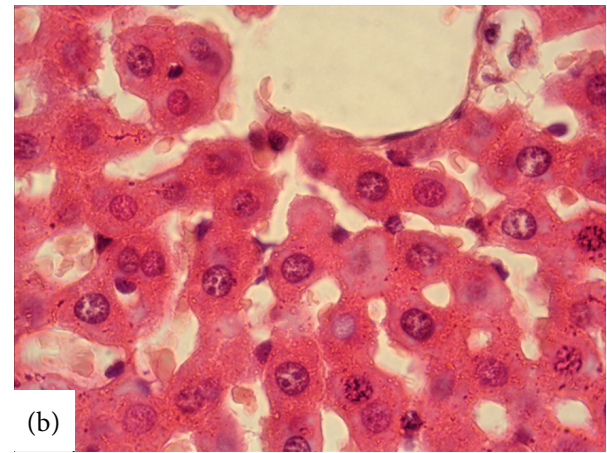

(b)

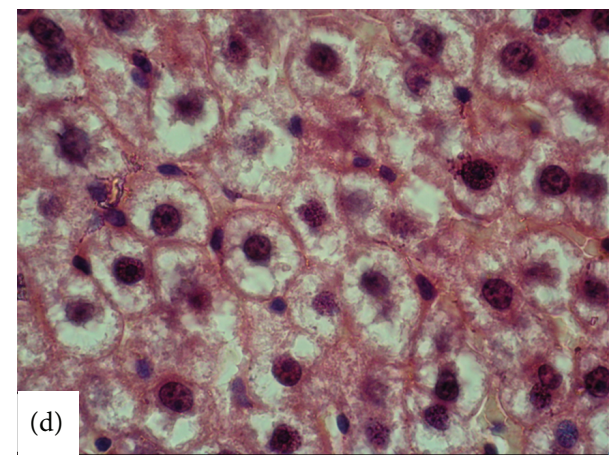

(d)

Figure 2: Liver histopathology ((a)-(b)): normal group liver, H\&E ( $\times 40$ and $\times 100$ magnification), and ((c)-(d)): hepatosteatosis group liver (macrovesicular steatosis in liver cytoplasm). 
rats $(P<0.00001)$. However, mean level of latency time in rats with hepatosteatosis treated with ICV exenatide was statistically significantly increased than that of rats with hepatosteatosis treated with ICV $\mathrm{NaCl}(P<0.001)$.

\section{Discussion}

Overconsumption of sugar-sweetened beverages promotes the development of overweight and is associated with metabolic disturbances, including intrahepatic fat accumulation and metabolic syndrome [17]. In the present study, macrovesicular hepatosteatosis was found in rat that received fructose overconsumption. And also it was found that cognitive performance (decreased latency time) has been impaired in rat with hepatosteatosis compared to normal rat. However, cognitive functions were improved with GLP-1 analog such as exenatide treatment.

Diet can affect brain plasticity and cognitive functions such as learning and memory [18]. A high fructose diet produces large increases in plasma triglyceride concentrations and liver mass [19]. In addition to increases in visceral adipose tissue [20-22] and liver mass [23,24] with high fructose diet in both male and female rats, behavioral status can change. In previous studies [25-27], acute injections of fructose have affected the cognitive functions in animals. Likewise, Ross et al. [28] reported that a high fructose diet impaired spatial water maze memory in male rats. Likewise, in the present study, mean levels of latency time were statistically significantly decreased in rats with hepatosteatosis than those of normal rats. However, Bruggeman et al. [29] suggested that the metabolism of fructose and the effects of a high fructose diet on learning and memory might be sex dependent.

GLP-1, an endogenous 30-amino-acid peptide produced in enteroendocrine cells of intestine, stimulates glucosedependent insulin secretion [30, 31]. And also GLP-1 and GLP-1R have been considered a therapeutic target in neurodegenerative and cognitive disorders throughout the central and peripheral nervous systems $[14,15,32,33]$. In a previous study, Oka et al. [14] indicated that GLP-1 receptors existed in the hippocampus and are involved in modulating hippocampal activity through an increase in the release of excitatory amino acid transmitters. Likewise, Perry et al. [32] reported that GLP-1R has been considered a therapeutic target in neurodegenerative and cognitive disorders throughout the central and peripheral nervous systems. And also GLP-1 has been reported to cross the blood-brain barrier (BBB) and facilitate insulin signaling [34, 35]; exenatide, a GLP-1 receptor agonist, could enhance neuronal progenitor proliferation in the brain of diabetic mouse [35]. Recently, Chen et al. [36] suggested that GLP-1 receptor agonist can protect neurons from diabetes-associated glucose metabolic dysregulation insults in vitro and from ICV streptozotocin insult in vivo. In another study, Gault et al. [37] showed that GLP-1 receptor agonist therapy improved cognitive function and ameliorated impaired hippocampal synaptic plasticity in dietary-induced obesity. In the present study, we found that mean levels of latency time in rats treated with ICV exenatide were increased than those of rats treated with ICV $\mathrm{NaCl}$.
To our findings, exenatide treatment improved learning and memory performance in rats with hepatosteatosis and metabolic syndrome. So, it may be a candidate for alleviation of memory and cognitive dysfunctions in metabolic disorders.

In summary, memory performance falls off in rats with hepatosteatosis feeding with fructose (decreased latency time). However, GLP-1 ameliorates cognitive functions (increased latency time) in rats with hepatosteatosis and related metabolic syndrome.

\section{Conflict of Interests}

The authors declare that there is no conflict of interests regarding the publication of this paper.

\section{References}

[1] E. Tomas, J. A. Wood, V. Stanojevic, and F. Habener, "Glucagonlike peptide-1(9-36)amide metabolite inhibits weight gain and attenuates diabetes and hepatic steatosis in diet-induced obese mice," Diabetes, Obesity and Metabolism, vol. 13, no. 1, pp. 26-33, 2011.

[2] L. Luo, M. Yang, Q. Hao, J. Yue, and B. Dong, "Cross-sectional study examining the association between metabolic syndrome and cognitive function among the oldest old," Journal of the American Medical Directors Association, vol. 14, no. 2, pp. 105108, 2013.

[3] K. F. Yates, V. Sweat, P. L. Yau, M. M. Turchiano, and A. Convit, "Impact of metabolic syndrome on cognition and brain: a selected review of the literature," Arteriosclerosis, Thrombosis, and Vascular Biology, vol. 32, no. 9, pp. 2060-2067, 2012.

[4] Y. D. Reijmer, E. van den Berg, J. M. Dekker et al., "The metabolic syndrome, atherosclerosis and cognitive functioning in a non-demented population: the Hoorn Study," Atherosclerosis, vol. 219, no. 2, pp. 839-845, 2011.

[5] A. S. Watts, N. Loskutova, J. M. Burns, and D. K. Johnson, "Metabolic syndrome and cognitive decline in early Alzheimer's disease and healthy older adults," Journal of Alzheimer's Disease, vol. 35, no. 2, pp. 253-265, 2013.

[6] C. L. Liu, M. H. Lin, L. N. Peng et al., "Late-life metabolic syndrome prevents cognitive decline among older men aged 75 years and over: One-Year Prospective Cohort Study," The Journal of Nutrition, Health \& Aging, vol. 17, no. 6, pp. 523-526, 2013.

[7] M. Muller, F. van Raamt, F. L. Visseren et al., "Metabolic syndrome and cognition in patients with manifest atherosclerotic disease: the SMART Study," Neuroepidemiology, vol. 34, no. 2, pp. 83-89, 2010.

[8] C. Hölscher, "The role of GLP-1 in neuronal activity and neurodegeneration," Vitamins \& Hormones, vol. 84, pp. 331-354, 2010.

[9] X. Su, X. Feng, N. Terrando et al., "Dysfunction of inflammation-resolving pathways is associated with exaggerated postoperative cognitive decline in a rat model of the metabolic syndrome," Molecular Medicine, vol. 18, no. 1, pp. 1481-1490, 2013.

[10] M. T. Heneka, F. Nadrigny, T. Regen et al., "Locus ceruleus controls Alzheimer's disease pathology by modulating microglial functions through norepinephrine," Proceedings of the National 
Academy of Sciences of the United States of America, vol. 107, no. 13, pp. 6058-6063, 2010.

[11] J. Hwang, H. Hwang, H.-W. Lee, and K. Suk, "Microglia signaling as a target of donepezil," Neuropharmacology, vol. 58, no. 7, pp. 1122-1129, 2010.

[12] D. Jardanhazi-Kurutz, M. P. Kummer, D. Terwel, K. Vogel, A. Thiele, and M. T. Heneka, "Distinct adrenergic system changes and neuroinflammation in response to induced locus ceruleus degeneration in APP/PS1 transgenic mice," Neuroscience, vol. 176, pp. 396-407, 2011.

[13] Y. Li, T. Perry, M. S. Kindy et al., "GLP-1 receptor stimulation preserves primary cortical and dopaminergic neurons in cellular and rodent models of stroke and Parkinsonism," Proceedings of the National Academy of Sciences of the United States of America, vol. 106, no. 4, pp. 1285-1290, 2009.

[14] J. I. Oka, N. Goto, and T. Kameyama, "Glucagon-like peptide-1 modulates neuronal activity in the rat's hippocampus," Neuroreport, vol. 10, no. 8, pp. 1643-1646, 1999.

[15] M. J. During, L. Cao, D. S. Zuzga et al., "Glucagon-like peptide1 receptor is involved in learning and neuroprotection," Nature Medicine, vol. 9, no. 9, pp. 1173-1179, 2003.

[16] S. W. French, K. Miyamoto, and H. Tsukamoto, "Ethanolinduced hepatic fibrosis in the rat: role of the amount of dietary fat," Alcoholism: Clinical and Experimental Research, vol. 10, supplement 6, pp. 13-19, 1986.

[17] A. Sheludiakova, K. Rooney, and R. A. Boakes, "Metabolic and behavioural effects of sucrose and fructose/glucose drinks in the rat," European Journal of Nutrition, vol. 51, no. 4, pp. 445-454, 2012.

[18] A. Lindqvist, P. Mohapel, B. Bouter et al., "High-fat diet impairs hippocampal neurogenesis in male rats," European Journal of Neurology, vol. 13, no. 12, pp. 1385-1388, 2006.

[19] G. D'Angelo, A. A. Elmarakby, D. M. Pollock, and D. W. Stepp, "Fructose feeding increases insulin resistance but not blood pressure in Sprague-Dawley rats," Hypertension, vol. 46, no. 4, pp. 806-811, 2005.

[20] A. Alzamendi, A. Giovambattista, A. Raschia et al., "Fructoserich diet-induced abdominal adipose tissue endocrine dysfunction in normal male rats," Endocrine, vol. 35, no. 2, pp. 227-232, 2009.

[21] A. Alzamendi, D. Castrogiovanni, R. C. Gaillard, E. Spinedi, and A. Giovambattista, "Increased male offspring's risk of metabolic-neuroendocrine dysfunction and overweight after fructose-rich diet intake by the lactating mother," Endocrinology, vol. 151, no. 9, pp. 4214-4223, 2010.

[22] Z. Zakula, G. Koricanac, S. Tepavcevic, M. Stojiljkovic, T. Milosavljevic, and E. R. Isenovic, "Impairment of cardiac insulin signaling in fructose-fed ovariectomized female Wistar rats," European Journal of Nutrition, vol. 50, no. 7, pp. 543-551, 2011.

[23] K. R. Bruckdorfer, I. H. Khan, and J. Yudkin, "Fatty acid synthetase activity in the liver and adipose tissue of rats fed with various carbohydrates," Biochemical Journal, vol. 129, no. 2, pp. 439-446, 1972.

[24] A. E. Bergstra, A. G. Lemmens, and A. C. Beynen, "Dietary fructose vs. glucose stimulates nephrocalcinogenesis in female rats," The Journal of Nutrition, vol. 123, no. 7, pp. 1320-1327, 1993.

[25] C. Messier and N. M. White, "Memory improvement by glucose, fructose, and two glucose analogs: a possible effect on peripheral glucose transport," Behavioral and Neural Biology, vol. 48 , no. 1 , pp. 104-127, 1987.
[26] A. E. Petro, J. Cotter, D. A. Cooper, J. C. Peters, S. J. Surwit, and R. S. Surwit, "Fat, carbohydrate, and calories in the development of diabetes and obesity in the C57BL/6J Mouse," Metabolism: Clinical and Experimental, vol. 53, no. 4, pp. 454-457, 2004.

[27] W. A. Rodriguez, C. A. Horne, A. N. Mondragon, and D. D. Phelps, "Comparable dose-response functions for the effects of glucose and fructose on memory," Behavioral and Neural Biology, vol. 61, no. 2, pp. 162-169, 1994.

[28] A. P. Ross, T. J. Bartness, J. G. Mielke, and M. B. Parent, "A high fructose diet impairs spatial memory in male rats," Neurobiology of Learning and Memory, vol. 92, no. 3, pp. 410-416, 2009.

[29] E. C. Bruggeman, C. Li, A. P. Ross et al., "A high fructose diet does not affect amphetamine self-administration or spatial water maze learning and memory in female rats," Pharmacology Biochemistry and Behavior, vol. 99, no. 3, pp. 356-364, 2011.

[30] B. Kreymann, G. Williams, M. A. Ghatei, and S. R. Bloom, "Glucagon-like peptide-17-36: a physiological incretin in man," The Lancet, vol. 330, no. 8571, pp. 1300-1304, 1987.

[31] B. Ahren, H. Larsson, and J. J. Holst, "Effects of glucagon-like peptide-1 on islet function and insulin sensitivity in noninsulindependent diabetes mellitus," The Journal of Clinical Endocrinology \& Metabolism, vol. 82, no. 2, pp. 473-478, 1997.

[32] T. Perry, H. W. Holloway, A. Weerasuriya et al., "Evidence of GLP-1-mediated neuroprotection in an animal model of pyridoxine-induced peripheral sensory neuropathy," Experimental Neurology, vol. 203, no. 2, pp. 293-301, 2007.

[33] J. Oka, E. Suzuki, N. Goto, and T. Kameyama, "Endogenous GLP-1 modulates hippocampal activity in $\beta$-amyloid proteintreated rats," Neuroreport, vol. 10, no. 14, pp. 2961-2964, 1999.

[34] S. Gengler, P. L. McClean, R. McCurtin, V. A. Gault, and C. Hölscher, "Val(8)GLP-1 rescues synaptic plasticity and reduces dense core plaques in APP/PS1 mice," Neurobiology of Aging, vol. 33, no. 2, pp. 265-276, 2012.

[35] A. J. Kastin, V. Akerstrom, and W. Pan, "Interactions of glucagon-like peptide-1 (GLP-1) with the blood-brain barrier," Journal of Molecular Neuroscience, vol. 18, no. 1-2, pp. 7-14, 2002.

[36] S. Chen, A. R. Liu, F. M. An, W. B. Yao, and X. D. Gao, "Amelioration of neurodegenerative changes in cellular and rat models of diabetes-related Alzheimer's disease by exendin-4," Age, vol. 34, no. 5, pp. 1211-1224, 2012.

[37] V. A. Gault, W. D. Porter, P. R. Flatt, and C. Hölscher, "Actions of exendin-4 therapy on cognitive function and hippocampal synaptic plasticity in mice fed a high-fat diet," International Journal of Obesity, vol. 34, no. 8, pp. 1341-1344, 2010. 


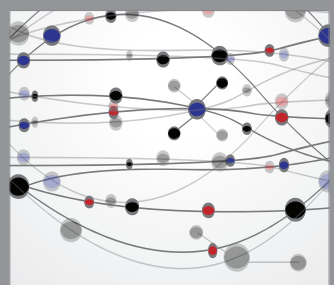

The Scientific World Journal
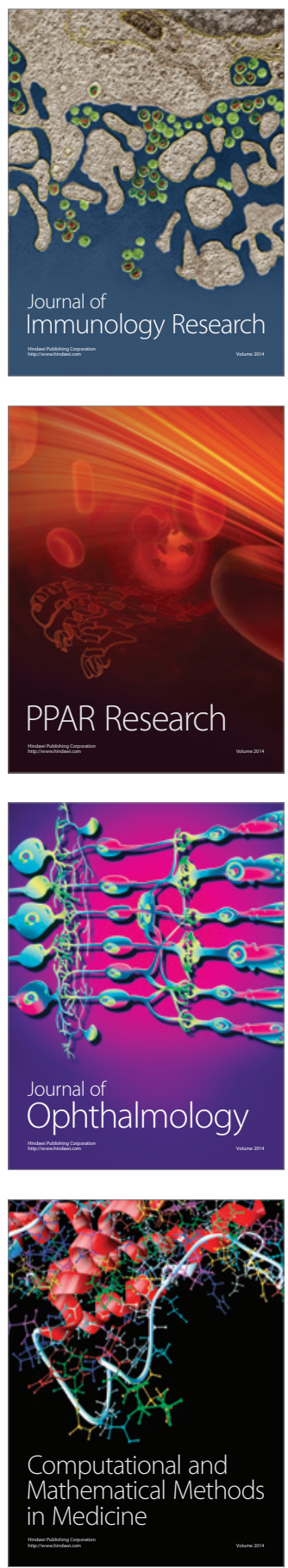

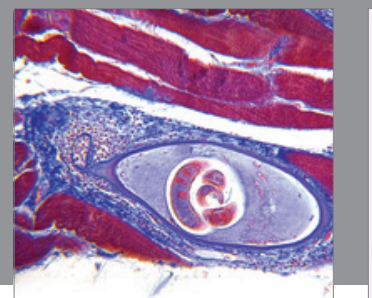

Gastroenterology

Research and Practice
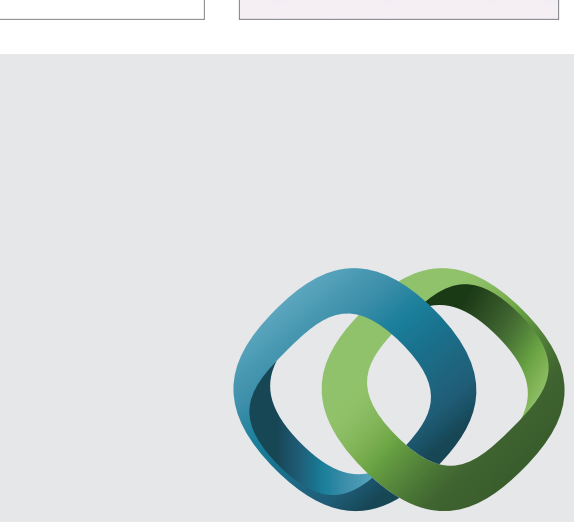

\section{Hindawi}

Submit your manuscripts at

http://www.hindawi.com
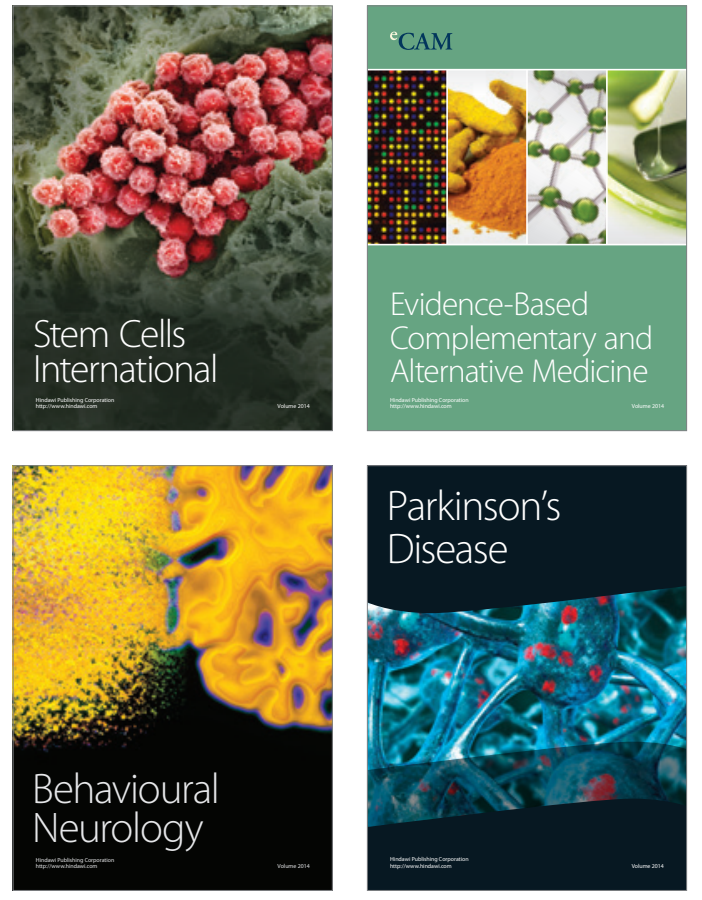
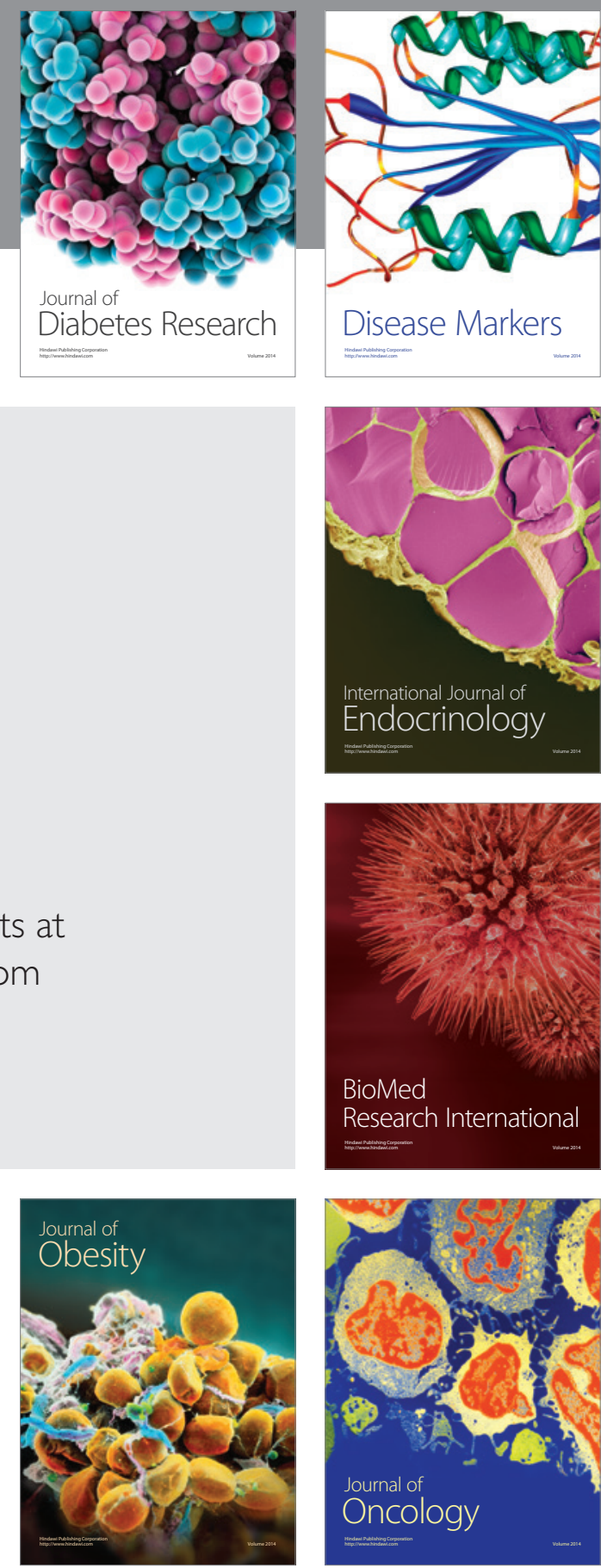

Disease Markers
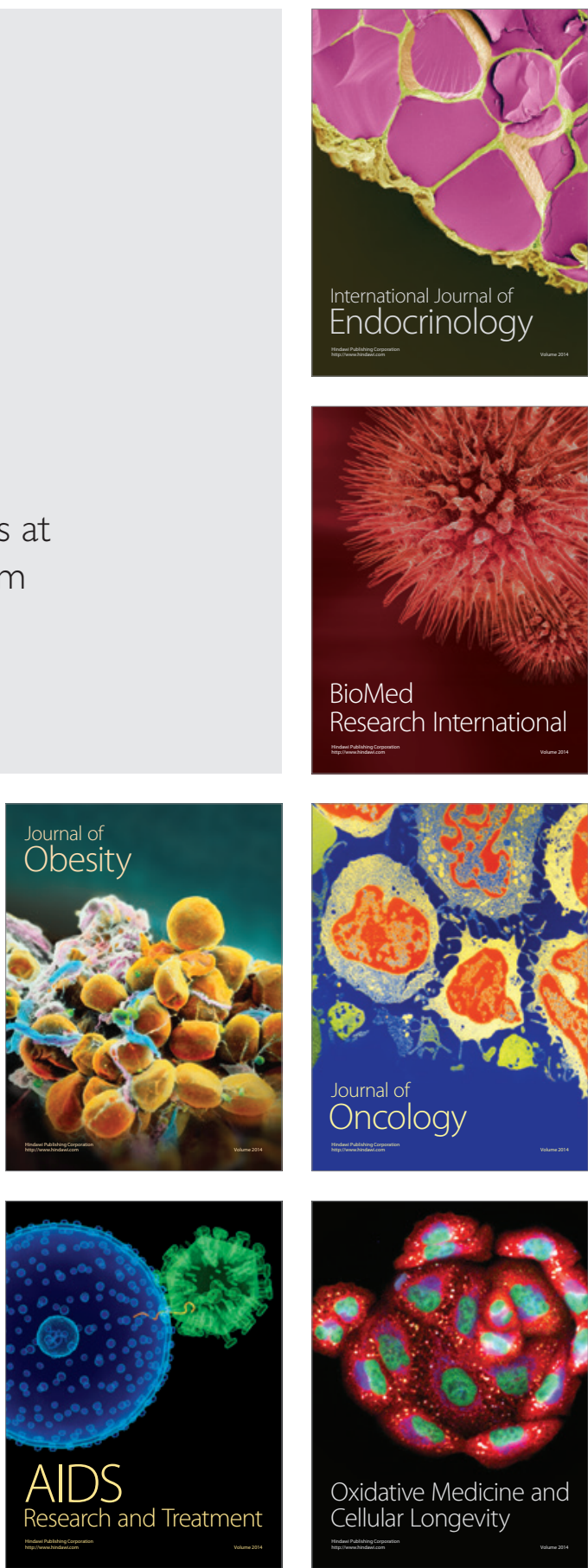